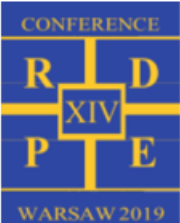

\title{
Various inlet spiral geometries in 1MW steam turbine
}

\author{
Arkadiusz Koprowski ${ }^{1}$, Dominik Gotowski ${ }^{1}$, Romuald Rządkowski ${ }^{1}$, and Ryszard Szczepanik $^{2}$ \\ ${ }^{1}$ Institute of Fluid-Flow Machinery Polish Academy of Sciences, Fiszera 14, 80-952 Gdansk, akoprowski@imp.gda.pl, Poland \\ ${ }^{2}$ Air Force Institute of Technology, Księcia Bolesława 6, 01-494 Warsaw, ryszard.szczepanik@itwl.pl, Poland
}

\begin{abstract}
A bstract. In small turbines, inlets can be designed using an inlet spiral. This paper analyses the efficiency of eight turbine variants, including seven with three stator and rotor blades and inlet spirals of various geometries, and one variant with a spiral, three stages and an outlet. This involves a 3D steady viscous flow using A NSY S CFX. The analysis shows that the spiral has a considerable influence on turbine efficiency.
\end{abstract}

\section{Introduction}

Steam turbine inlets usually comprise inlet boxes for partial and full admission. Inlet design in small turbines is normally simplified to economise on production costs.

Kryłłowicz et al. [1] described in a condensing steam turbine $(50 \mathrm{~kW})$ and a back pressure turbine $(165 \mathrm{~kW})$. The general parameters are: inlet temperature $340 \mathrm{C}$, inlet pressure 12 bar, mass flow $270 \mathrm{~kg} / \mathrm{h}$ and rotation speed $6276 \mathrm{rpm}$. The turbine inlets are of the standard type used in turbines.

Škach and Uher [2] showed design process of stator blades for spiral inlets.

Hecker et al. [3] presented the design of spiral inlets. The structure and aerodynamics analyses were shown.

This paper for the first time studies different inlet spiral geometries for a $1 \mathrm{MW}$, three-stage steam turbine with a $30 \mathrm{t} / \mathrm{h}$ mass flow.

\section{Numerical studies}

ANSYS CFX was used to calculate steady viscous flow in four inlet spirals and three stages, each with 32 stator blades and 99 rotor blades. Design Modeller was used to create the geometries of rotor and stator blades as well as turbine inlets and outlets. TurboGrid was used to prepare the blade, inlet and outlet meshes.

The purpose of the analysis was to determine the efficiency of the eight turbine variants.

\subsection{Variant one}

Here, the circular pipe entered the rectangular channel of the spiral at a low angle to allow for a smoother flow. The outlet spiral leading the steam to the stator blades was in the form tapered diffuser (Fig. 1, 2). The inlet spiral caused a reversal of flow towards in the stator blades. There were 32 stator blades with an S-9012A profile [4].

A stall flow appeared in the inlet pipe and spiral as well as the stator blades when there was a flow velocity perpendicular to stator the pressure side in the first stage (Fig. 3, 4).

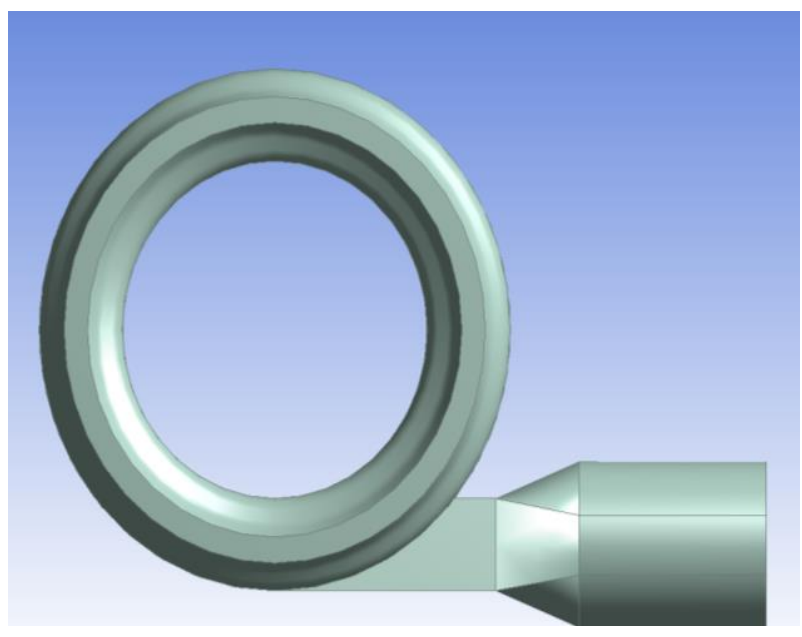

Fig. 1. Side view of Variant one spiral.

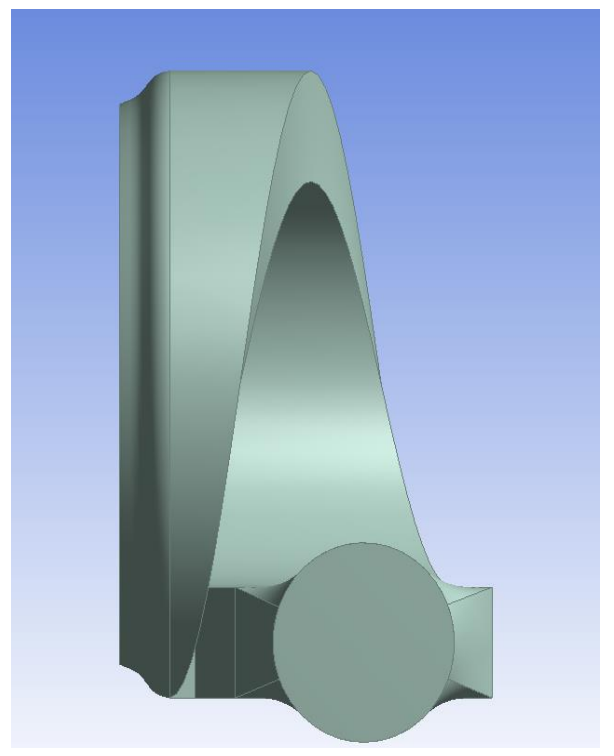

Fig. 2. Front view of variant one spiral.

According to the CFD calculations, the turbine generated $1.368 \mathrm{MW}$ with a mass flow of $9.78 \mathrm{~kg} / \mathrm{s}(35.21$ $\mathrm{t} / \mathrm{h}$ ) and an inlet pressure drop of $5.64 \mathrm{kPa}$ and was $86.17 \%$ efficient. 


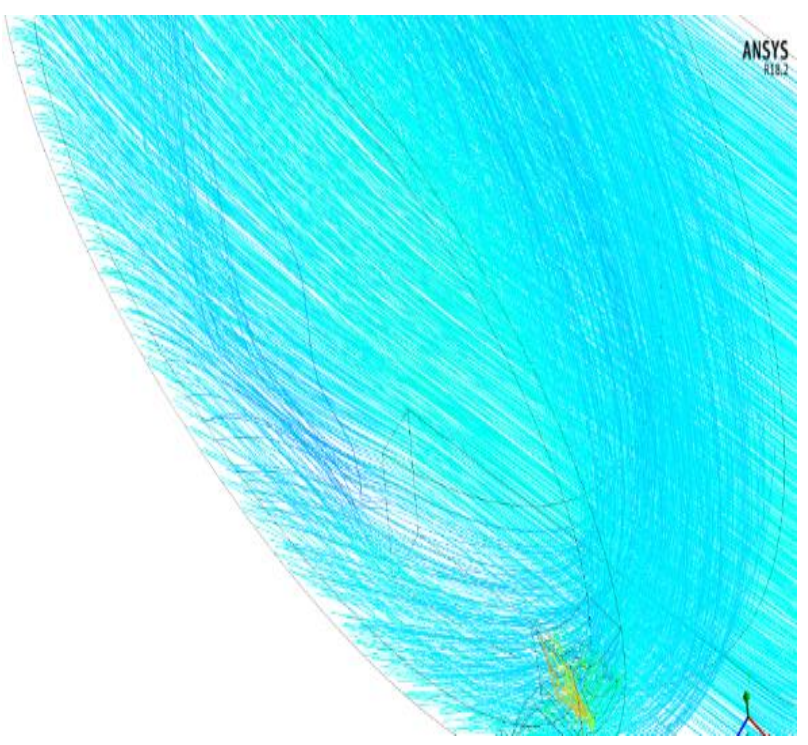

Fig. 3. Spiral inlet flow, variant one.

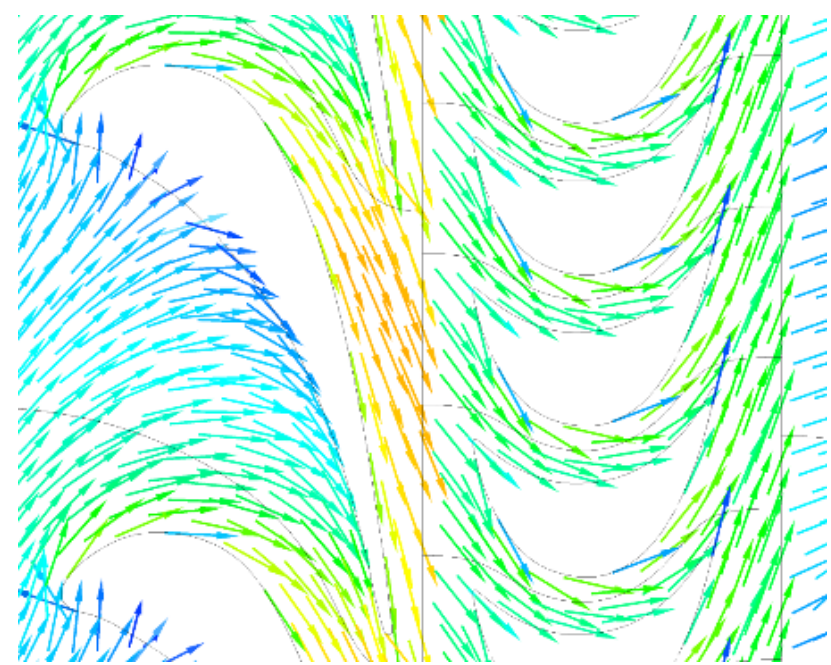

Fig. 4. Velocity field at 0.5 of stator blade, variant one.

\subsection{Variant two}

The geometry of the spiral in variant two was the same as in variant one. The differences concerned the profile of the first stator (S-5515A) [4] and the number of stator blades was increased to 39 . The altered stator blade profile prevented stall in the stator area and the velocity vector was no longer vertical to the pressure side (Fig. 5).

According to the CFD calculations, the turbine generated $1.516 \mathrm{MW}$ with a mass flow of $10.73 \mathrm{~kg} / \mathrm{s}$ $(38.64 \mathrm{t} / \mathrm{h})$ and an inlet pressure drop of $6.55 \mathrm{kPa}$, resulting in $86.9 \%$ efficiency. The altered first stator blade profile prevented steam flow stall around the stator blades and caused efficiency to rise from $86.17 \%$ to $86.9 \%$.

\subsection{Variant three}

The circular pipe entered the rectangular spiral channel at a zero angle. The first stator profile was S-9012A [4] and there were 32 stator blades. In contrast to variants one and two, where the steam flowed through the centre of the spiral, in variant three, the steam flowed down the inner side of the spiral. A diffusor was not applied in this case (Fig. 6, 7, 8).

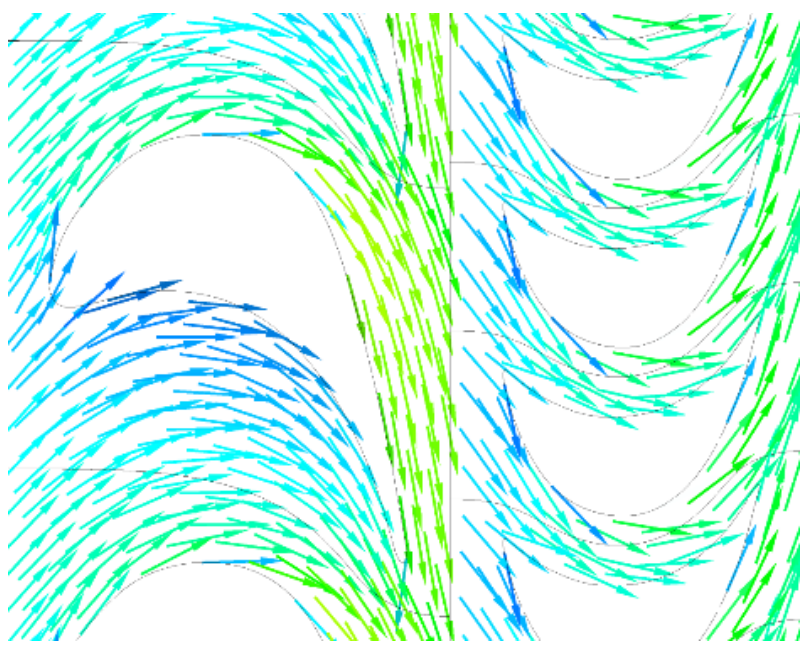

Fig. 5. Velocity field at 0.5 of the stator blade length, variant two.

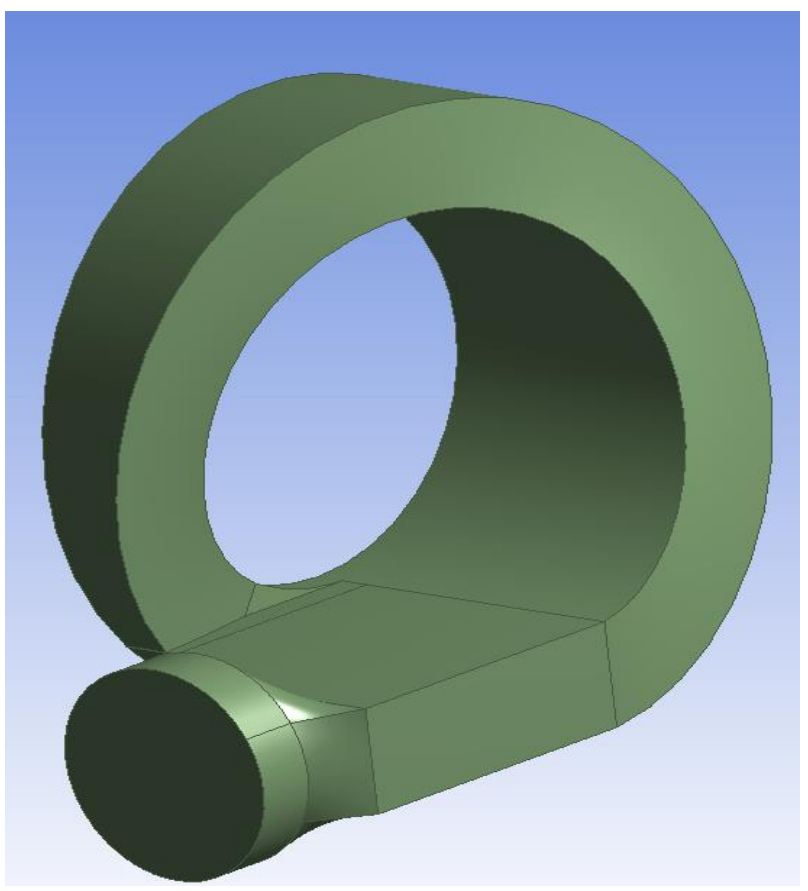

Fig. 6. Variant three spiral.

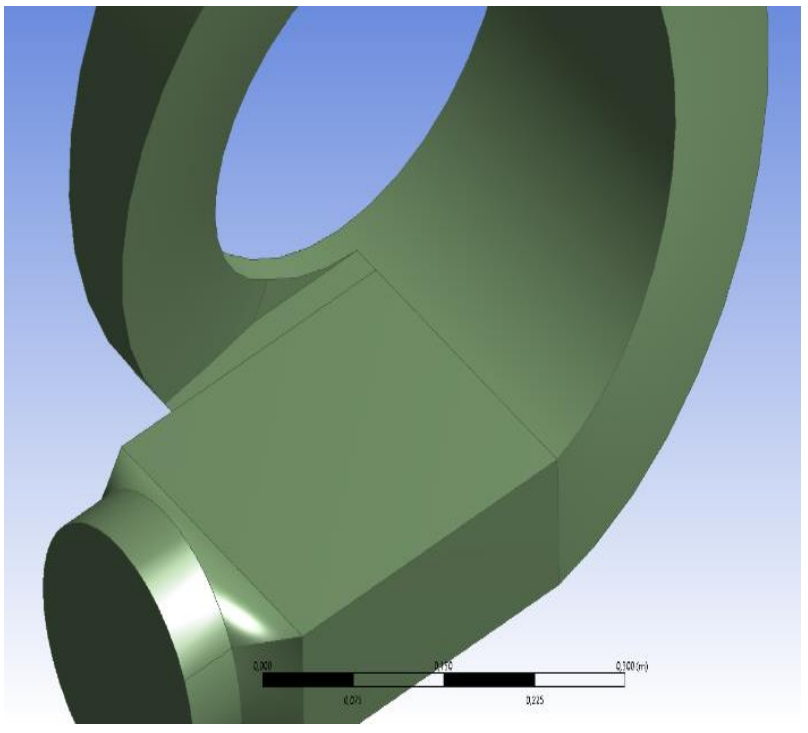

Fig. 7. Variant three spiral, enlarged. 


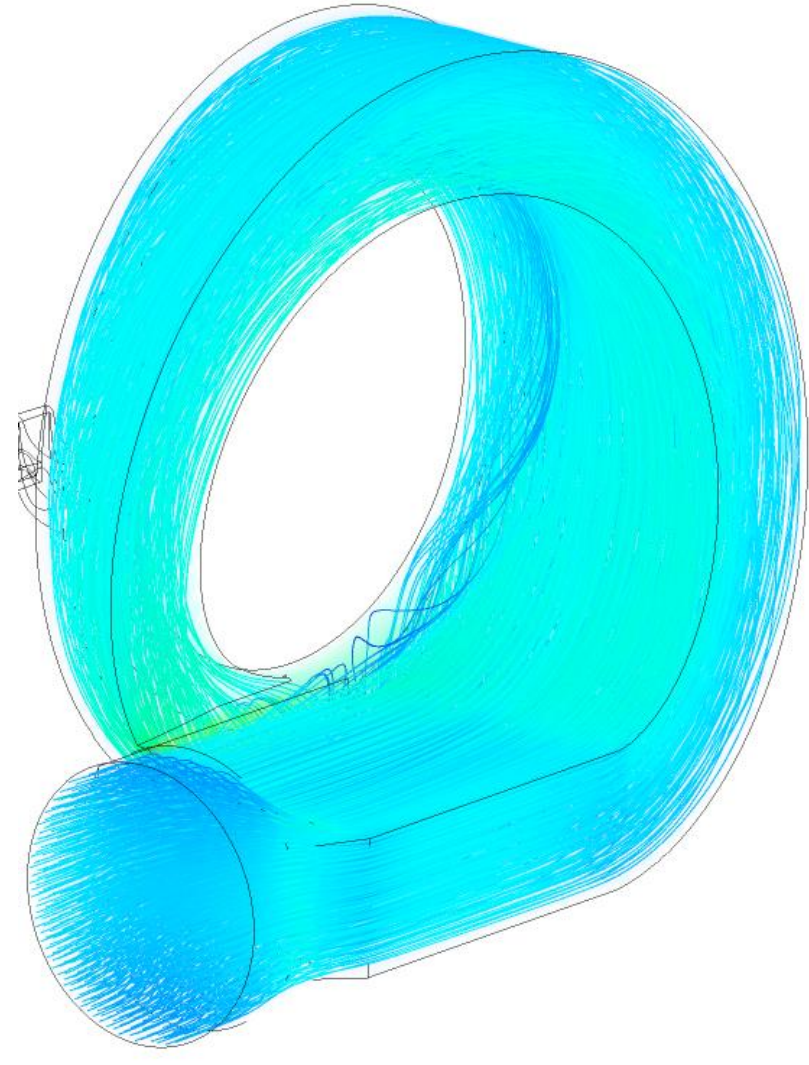

Fig. 8. Streamlines in inlet, variant three

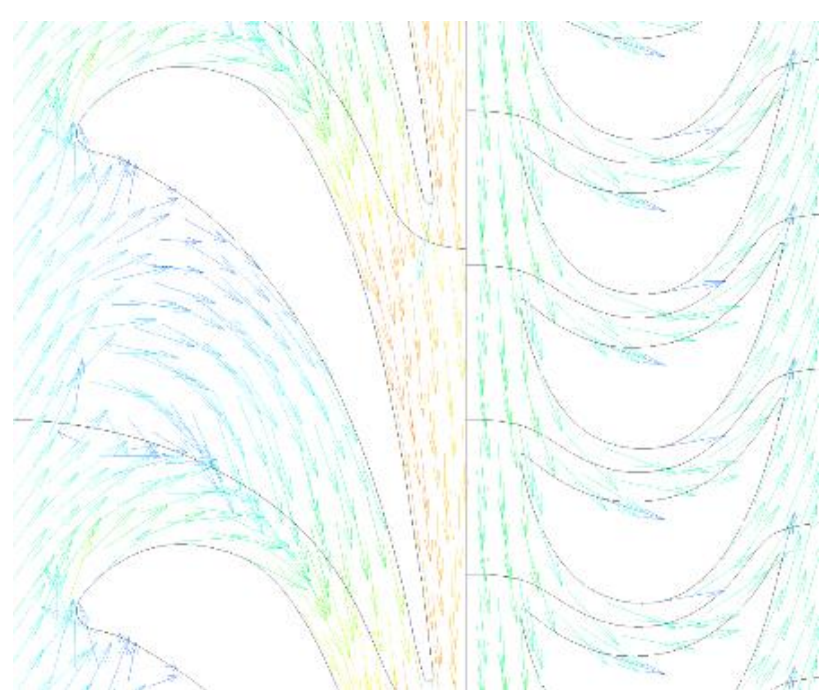

Fig. 9. Variant three velocity field at 0.5 stator blade length.

Due to the altered geometry, a stall appeared in the stator region (Fig. 9), causing efficiency to drop to $83.7 \%$.

According to the CFD calculations, the turbine generated 1.293 MW with a mass flow of $9.50 \mathrm{~kg} / \mathrm{s}(34.21$ $\mathrm{t} / \mathrm{h}$ ) and inlet pressure drop of $21.15 \mathrm{kPa}$. Reducing the inlet pipe angle to zero caused a perpendicular flow on the pressure side, as in Variant one, and the reduced efficiency to $83.7 \%$.

\subsection{Variant four}

Variants four and three had the same geometries, but the profile of the first stator blade in the former was altered to
(S-5515A) [4]. As in variant two, there were 39 stator blades.

The altered stator blade profile prevent stall at 0.5 length of the blade but a stall did occur in the root and at the tip (Fig. 10, 11).

The turbine generated $1.458 \mathrm{MW}$ with a mass flow of $10.49 \mathrm{~kg} / \mathrm{s}(37.75 \mathrm{t} / \mathrm{h})$ and an inlet pressure drop of $24.49 \mathrm{kPa}$. The variant four stator blade profile improved turbine efficiency from $83.7 \%$ to $85.69 \%$.

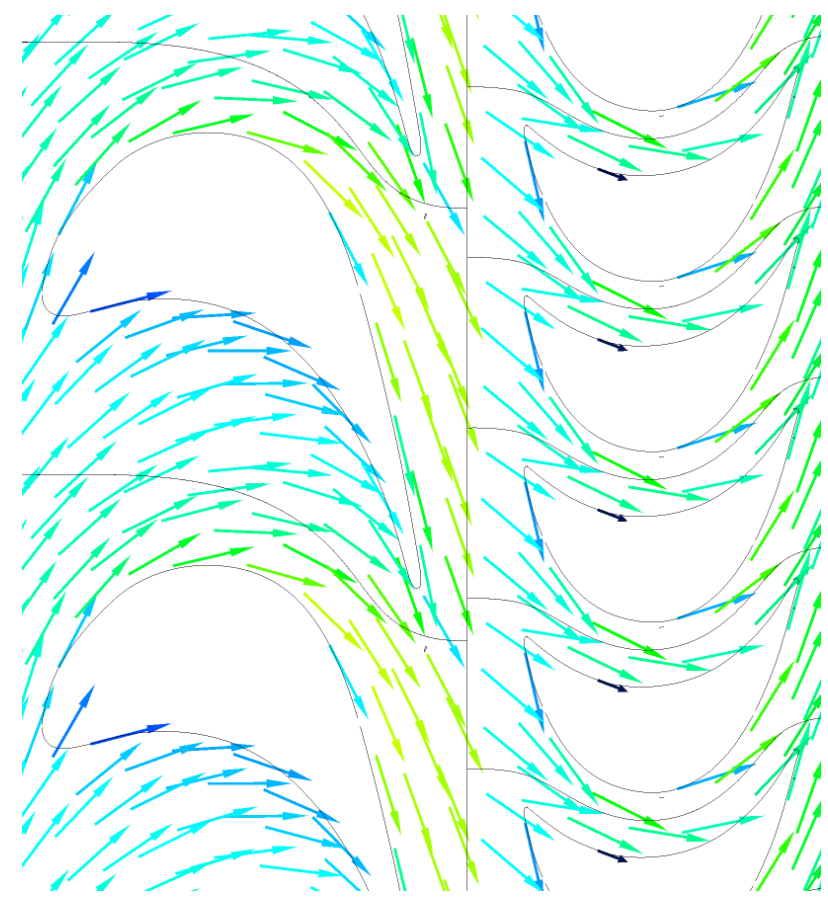

Fig. 10. Variant four velocity field at 0.5 of stator blade length.

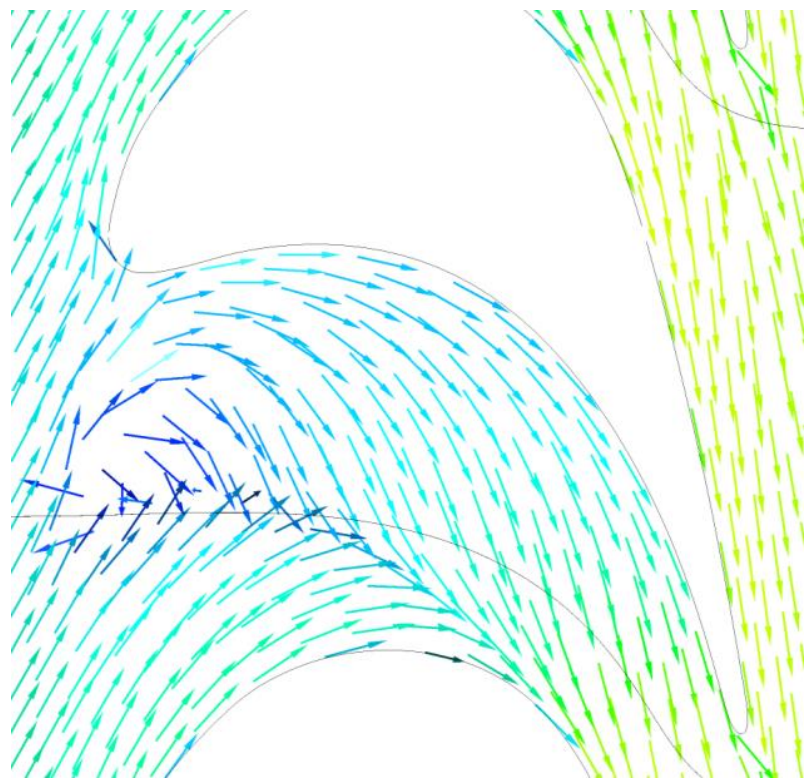

Fig. 11. Variant four velocity field at 0.05 of stator blade length.

\subsection{Variant five}

Variant 5 inlet spiral was altered to prevent flow reversal (Fig. 12, 13). The length if the first stator (S-9012A) [4] was reduced from $62.5 \mathrm{~mm}$ to $56 \mathrm{~mm}$ and there were 32 stator blades. In other stages, the number of stator blades 
was the same as in variants one to four. Fig.8 presents the flow velocity, which did not stall.

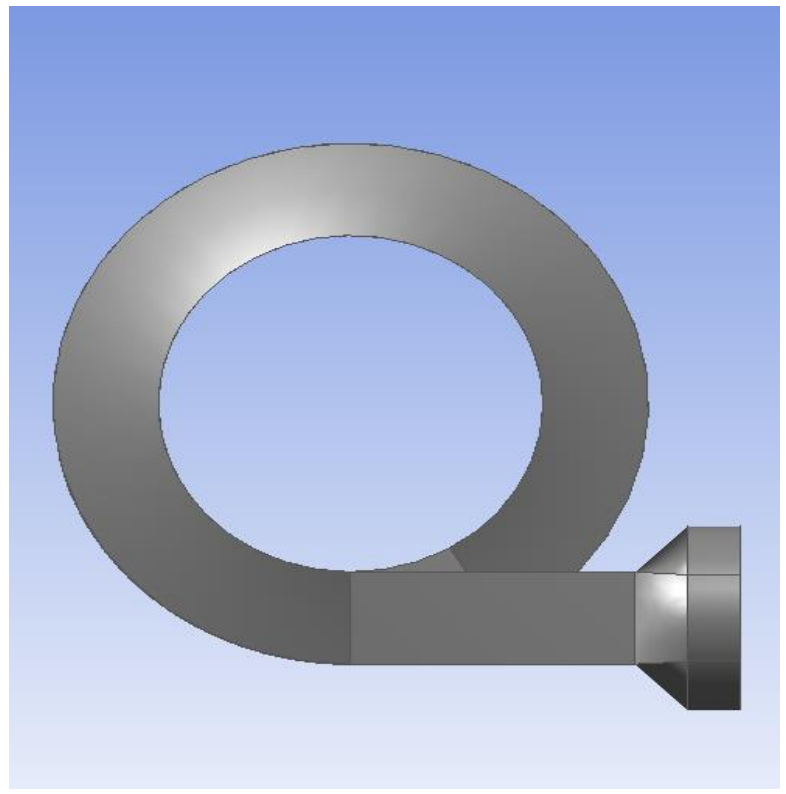

Fig. 12. Side view of variant five spiral.

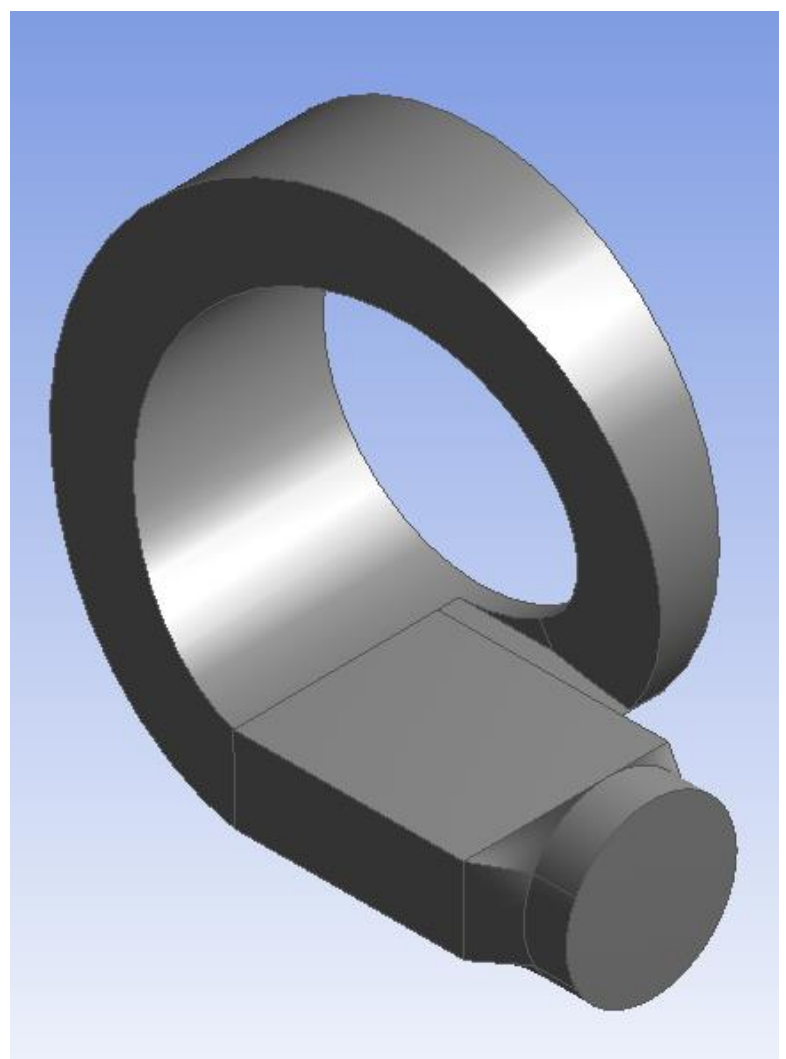

Fig. 13. Variant five inlet spiral.

The turbine generated $1.373 \mathrm{MW}$, with a mass flow of $9.68 \mathrm{~kg} / \mathrm{s}(34.86 \mathrm{t} / \mathrm{h})$ and a $20.99 \mathrm{kPa}$ pressure drop in the inlet. The variant five alterations improved turbine efficiency from $85.7 \%$ to $87.3 \%$. Fig. 14 presents the flow velocity, which did not stall.

\subsection{Variant six}

Here, the first stator blade profile (S-9012A) [4] was reduced from $62.5 \mathrm{~mm}$ to $54 \mathrm{~mm}$, blade thickness was reduced on the suction side and this variant included 32 stator blades.

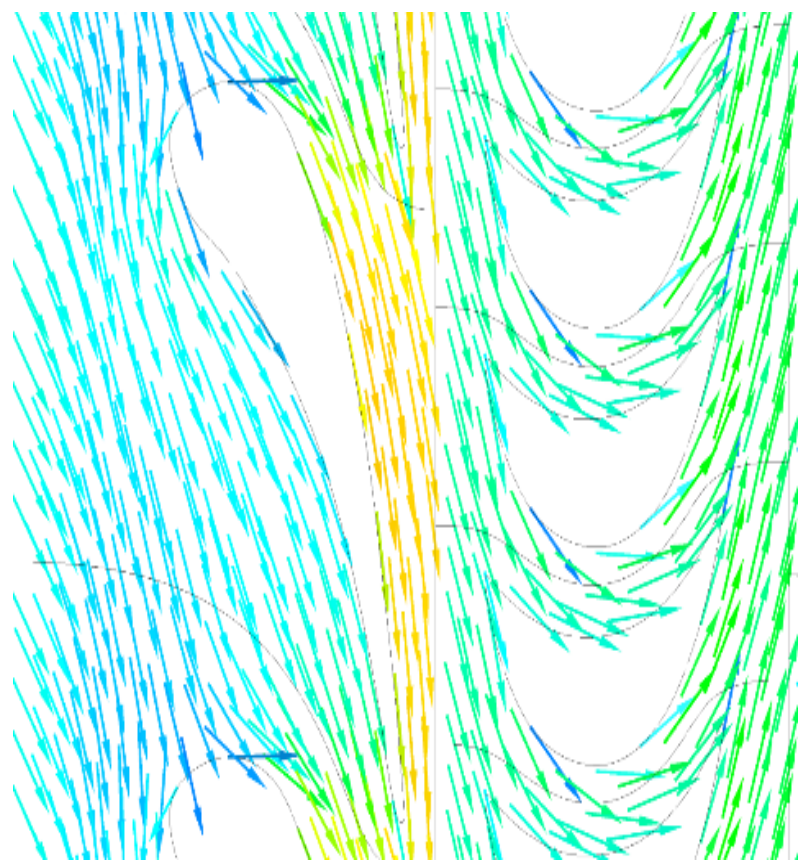

Fig. 14. Variant five velocity field at 0.5 of stator blade length.

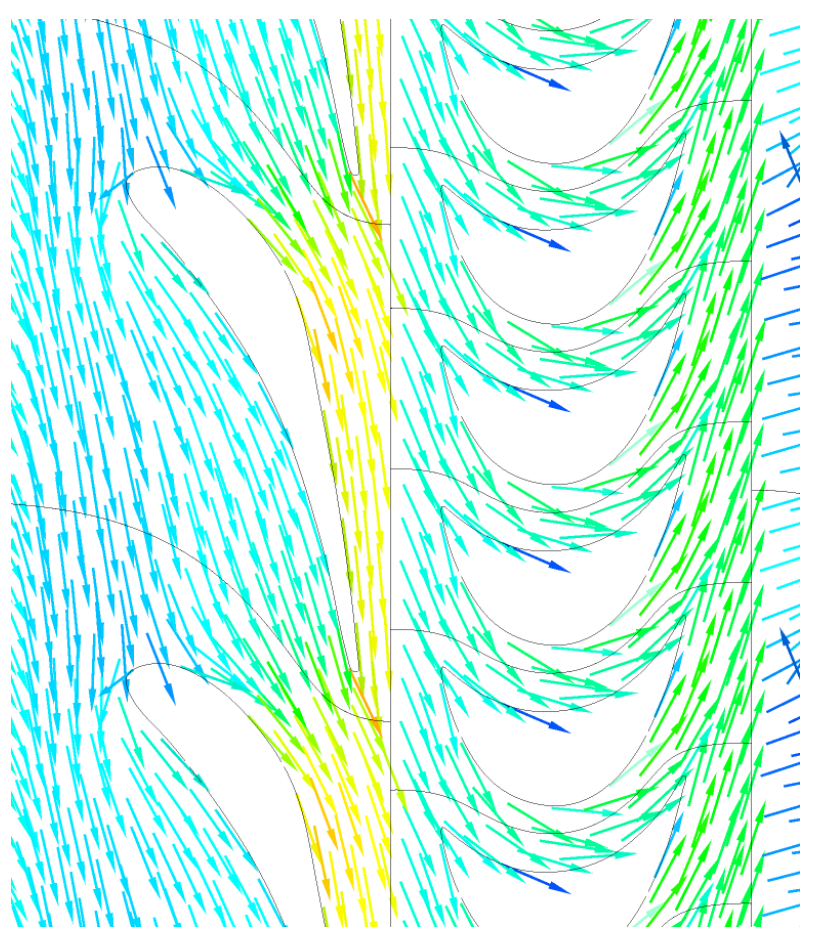

Fig. 15. Variant six velocity field at 0.5 of stator blade length

The turbine generated $1.428 \mathrm{MW}$ with a mass flow of $10.08 \mathrm{~kg} / \mathrm{s}(36.31 \mathrm{t} / \mathrm{h})$ and a $23.02 \mathrm{kPa}$ pressure drop at the inlet. The altered first stator blade profile in variant six reduced turbine efficiency from $87.3 \%$ to $87.15 \%$. Fig. 15 presents the flow velocity, which did not stall.

\subsection{Variant seven}

Two inlet pipes were applied in variant seven instead of one (Fig. 16, 17, 18).

The turbine generated $1.178 \mathrm{MW}$ with a mass flow $8.21 \mathrm{~kg} / \mathrm{s}(29.31 \mathrm{t} / \mathrm{h})$ and a $1.24 \mathrm{kPa}$ pressure drop at 
the inlet. The application of two pipe in variant seven improved turbine efficiency from $87.3 \%$ to $88.87 \%$. Fig. 19 presents the flow velocity, which did not stall.

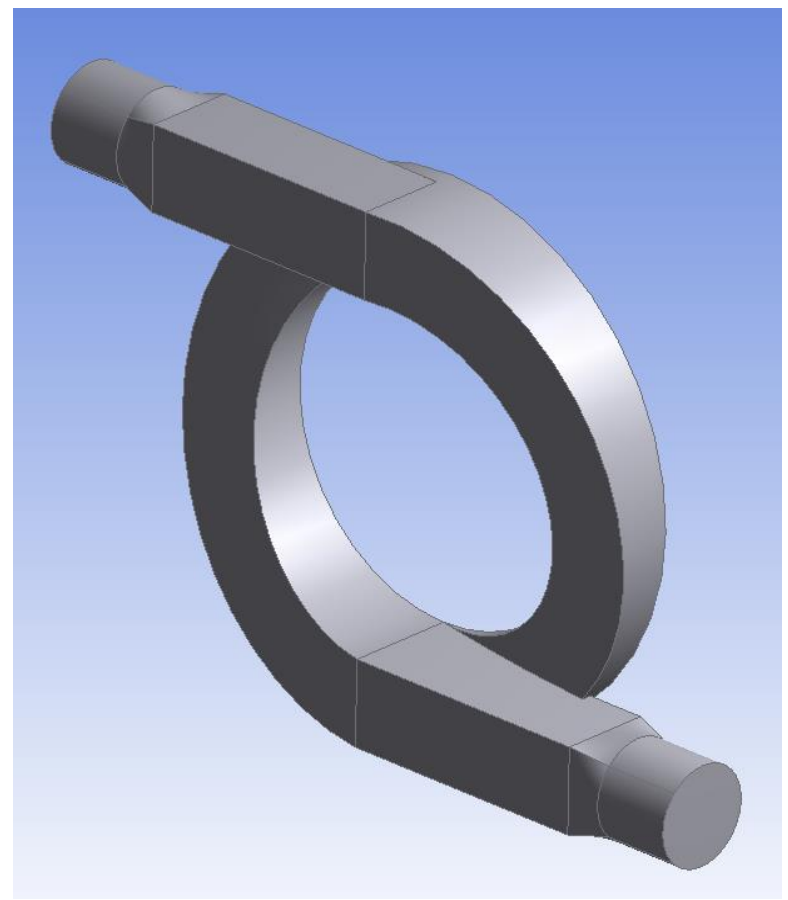

Fig. 16. Variant seven spiral.

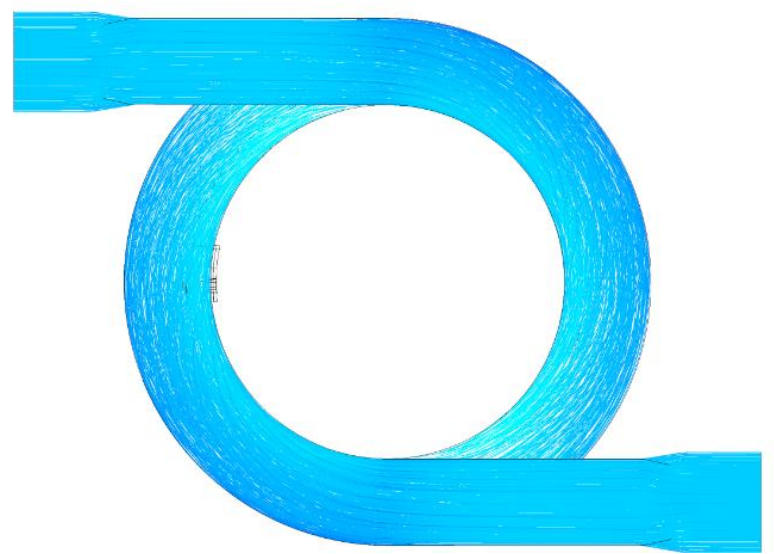

Fig. 17. Streamlines in inlet, variant seven

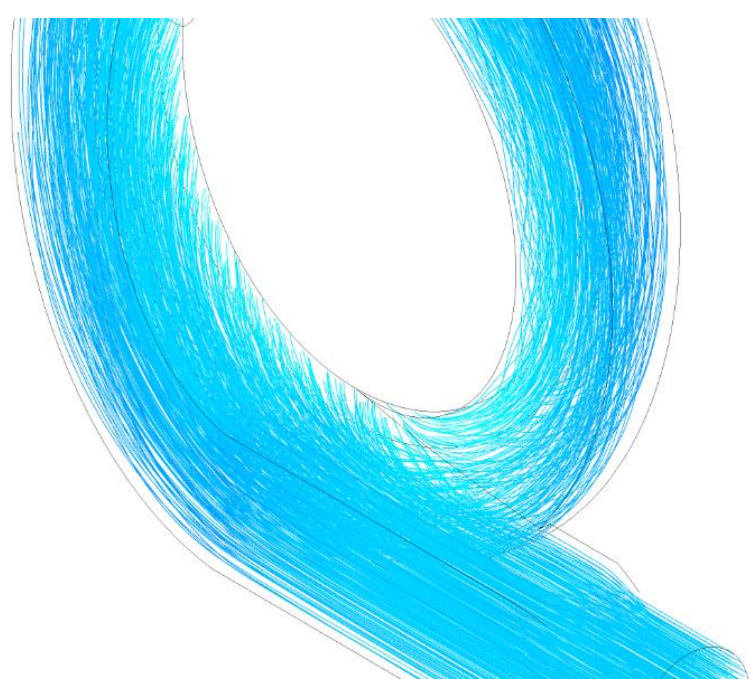

Fig. 18. Streamlines in inlet, variant seven

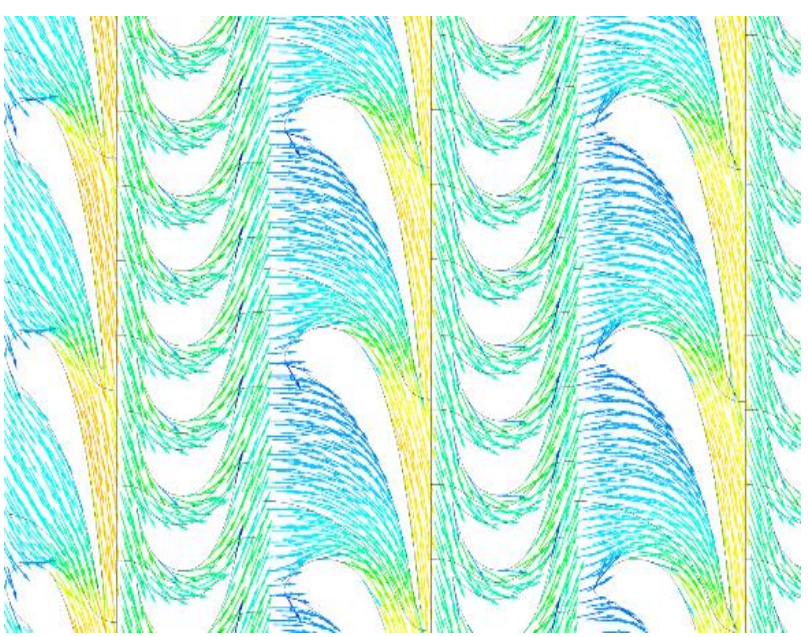

Fig. 19. Variant seven velocity field at 0.5 of stator blade length.

\subsection{Variant eight}

Variant eight had the same spiral and three stages as in variant seven, and the only difference was the addition of an outlet (Fig. 20, 21).

The turbine generated $1.100 \mathrm{MW}$ with $7.99 \mathrm{~kg} / \mathrm{s}$ $(28.76 \mathrm{t} / \mathrm{h})$ mass flow and $118 \mathrm{kPa}$ inlet pressure drop. The inclusion of the outlet reduced turbine efficiency from $88.87 \%$ (Variant seven) to $85.31 \%$. This was due to the fact that the outlet was causing the flow to whirl in many place (Fig. 23). Fig. 22 shows the velocity of the flow, which did not stall in the stator and rotor regions.

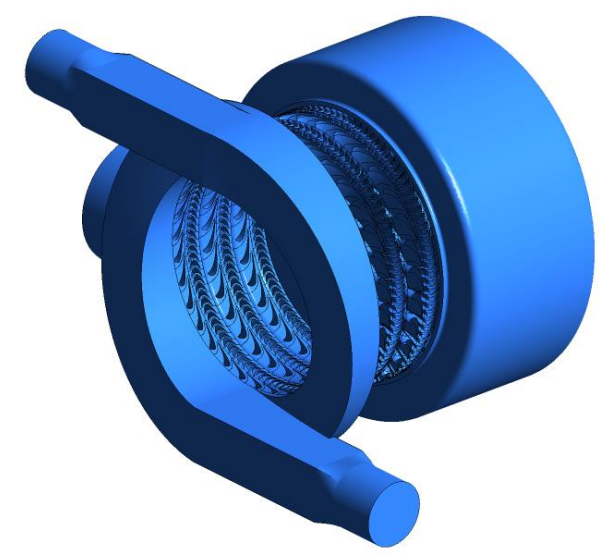

Fig. 20. Variant eight inlet with 3 stages and an outlet.

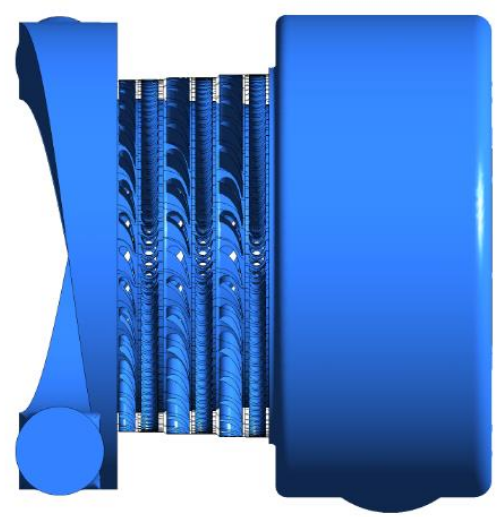

Fig. 21. Side view of variant eight. 


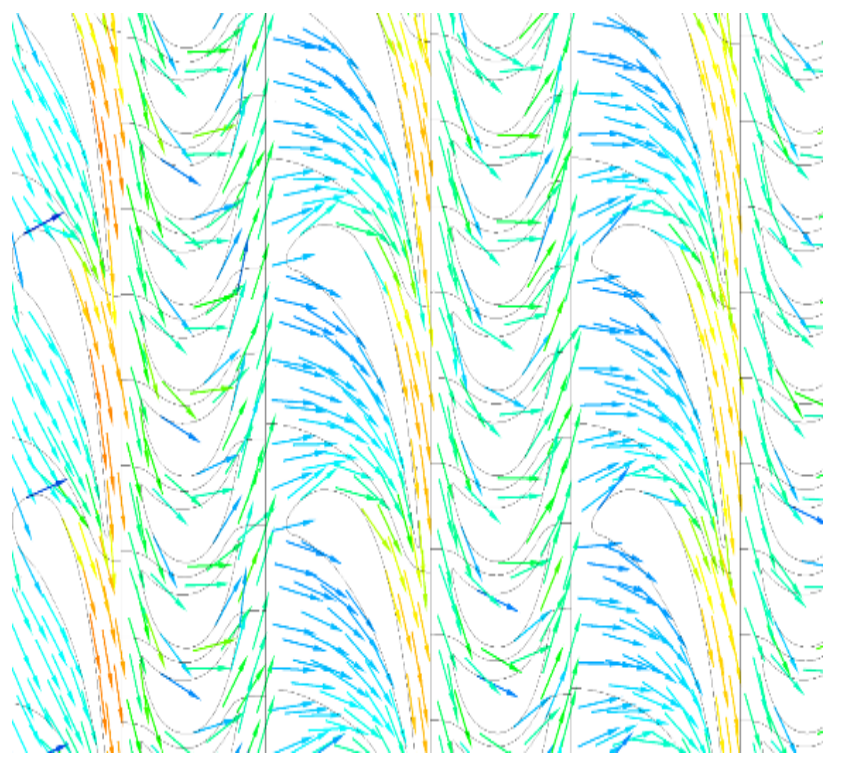

Fig. 22. Variant eight velocity field at 0.5 of stator blade length.

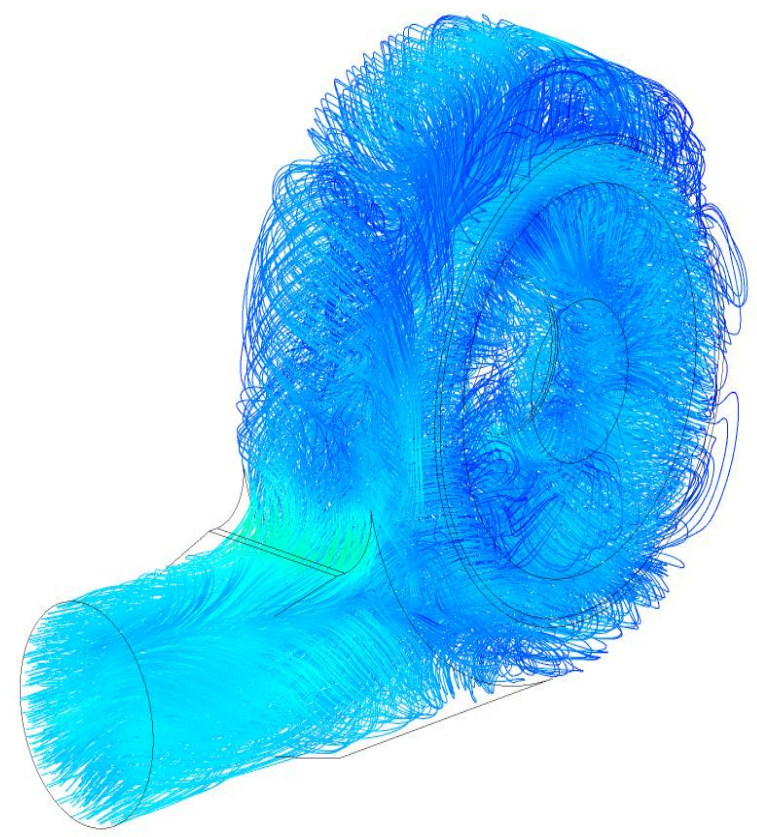

Fig. 23. Streamlines in outlet, variant 8

\section{Conclusions}

This paper for the first time analyses the flow in various inlet spirals in a $1 \mathrm{MW}$ steam turbine inlets. In addition to altering the spiral geometries, the stator blade profiles were also changed. Adding a second pipe to the inlet spiral improved efficiency from $87.3 \%$ to $88.87 \%$.

Efficiency was also increased changing the first stator blade profile from S-5515A to S-9012A.

The changed profile increased the mass flow, which could next be reduced by shortening of the length of the stator blades. In the last variant, an outlet was added to calculate the efficiency of the entire flow system. This reduced efficiency from $88.87 \%$ to $85.87 \%$.

\section{Acknowledgement}

The authors wish to acknowledge NCBiR for the financial support of this work (POIR.04.01.04-00-0116/17).

\section{References}

1. Kryłłowicz W., Liskiewicz G., Szwaja S., Small Steam Turbines for Distributed Power GenerationTechnical and Economic Condition, Energetyka, November, 719-722, (2015).

2. Škach R., Uher J., Spiral inlets for steam turbines, $36^{\text {th }}$ Meeting of Departments of Fluid Mechanics and Thermodynamics AIP Conference Proceedings 1889, 020038-1-020038-7, (2017).

3. Hecker S., Rohe A., Stoff H., Steam turbine inlet geometry from a structural and fluid dynamics point of view, Procedings of ASME Turbo Expo 2012

4. Dejcz M.E., Filipov G.A., Profile Collections of Axial Turbine Cascades, Maszinostrojenie (1965). 